\title{
Estratégias Didáticas Interdisciplinares: A construção de Terminais para o Ensino Ecológico e Consciente
}

\author{
Lucas P. Prestes ${ }^{1}$, Andréia S.Bos ${ }^{2}$, Gerson Klein ${ }^{1}$, Graziele Halmenschlager ${ }^{3}$ \\ Mauricio Rosa ${ }^{3}$, Milton Zaro ${ }^{1}$ \\ ${ }^{1}$ CINTED - Universidade Federal do Rio Grande do Sul (UFRGS) \\ Porto Alegre - RS - Brazil \\ ${ }^{2}$ IFRS - Instituto Federal do Rio Grande do Sul. \\ ${ }^{3}$ UNIRITTER - Centro Universitário Ritter dos Reis \\ \{lucas.plautz.prestes, andreia.bos, gersonklein,grazihal,prof.mauriciomr \\ \} @gmail.com, zaro@ufrgs.br
}

\begin{abstract}
Resumo. Este trabalho relata a integração entre os cursos de Jogos Digitais, Computação, Engenharias, Design e o Núcleo de Inclusão Digital (NID), como forma de ensino interdisciplinar e consciente no uso de tecnologias na educação. Utilizando-se da reciclagem de terminais, buscou-se a criação de estações de jogos digitais desenvolvidos por alunos que farão uso destes conhecimentos em startups ou criação de terminais interativos. O projeto consistiu na reciclagem consciente do lixo eletrônico, remodelagem da parte elétrica e mecânica, oficina de pintura e arte internacional, adaptação do sistema operacional e testes de aceitação do produto desenvolvidos por alunos em disciplinas com foco no ensino e aprendizagem colaborativa.
\end{abstract}

Palavras chave: totens, remodelagem, colaboração, design

\section{Interdisciplinary Didactic Strategies: The Construction of Terminals for Ecological and Conscious Education}

\begin{abstract}
This work reports the integration between the courses of Digital Games, Computing, Engineering, Design and the Nucleus of Digital Inclusion (NID), as a form of interdisciplinary and conscious teaching in the use of technologies in education. Utilizing terminal recycling, we sought the creation of digital game stations developed by students who will use this knowledge in startups or creation of interactive terminals. The project consisted of the conscious recycling of electronic waste, electrical and mechanical remodeling, painting and international art workshop, adaptation of the operating system and product acceptance tests developed by students in disciplines focused on teaching and collaborative learning.
\end{abstract}

Keywords: totens, remodeling, collaboration, design 


\section{Introdução}

Atualmente, muitos equipamentos ligados à informática são descartados e acabam virando sucata e, quando não reciclados adequadamente, viram poluentes em bacias hidrográficas ou em áreas de solo que poderiam ser utilizados para o plantio. Desta forma, torna-se fundamental pensar em alternativas que reduzam o impacto ambiental gerado pelo descarte inadequado desses equipamentos.

Estimativas do Greenpeace (2015) indicam que 50 milhões de toneladas de lixo eletrônico sejam geradas anualmente no nosso planeta. Segundo o Greenpeace, se a quantidade estimada de lixo eletrônico gerado a cada ano pudesse ser colocada em vagões de um trem, esse daria uma volta ao mundo. Já o Programa das Nações Unidas para o Meio Ambiente (PNUMA) calcula que a geração de lixo eletrônico global cresce a uma taxa de cerca de 40 milhões de toneladas por ano (Palop, 2010). No âmbito nacional, o cálculo é de 96,8 mil toneladas de computadores descartados anualmente. Em média, cada brasileiro descarta $0,5 \mathrm{~kg}$ de lixo eletrônico por ano, considerando apenas computadores (Ortácio, 2010).

O lixo eletrônico tem crescente atenção na última década (STEP, 2015), devido ao fato de que é uma, senão a maior, fonte de crescimento de resíduos sólidos em todo o mundo (PERKINS, 2014). Considerando que muitos outros fluxos de resíduos estão em declínio, o lixo eletrônico continua a crescer a uma taxa de aproximadamente 5\% ao ano. A Organização das Nações Unidas (ONU) prevê um crescimento de até $500 \%$ na próxima década em países desenvolvidos (STEP, 2015).

O Brasil está entre os maiores mercados mundiais de celulares e computadores, porém infelizmente não há uma política nacional para o descarte ou o reuso desse tipo de componentes. A Política Nacional de Resíduos Sólidos faz menção a responsabilidade de toda a cadeia de venda que contempla desde os fabricantes a revendedores na realização da logística reversa de resíduos sólidos, mas não regulamenta especificamente o lixo eletroeletrônico. Apesar disso, empresas como a Apple destaca-se por empregar a reciclagem e energia renovável em todo o processo de fabricação e reciclagem de seus produtos vendidos em todo o mundo. A preocupação da sociedade com o meio ambiente nos últimos anos faz com que as empresas começaram a compreender que podem obter ganhos financeiros e benefícios ambientais obtidos a partir de atividades da logística reversa (SILVA, 2012).

A partir dos estudos do impacto do lixo eletrônico associado a responsabilidade social e empresarial destes detritos em discussões abertas entre alunos e professores, buscou-se possíveis soluções para este problema de escala global. A partir deste dialogo, fomentou-se tornar este problema parte da sociedade acadêmica em busca de soluções sustentável e educadoras. Neste sentido, criou-se o projeto Terminais Digitais, cujo o objetivo é, através de atividades extracurricular, que alunos de diferentes cursos apresentassem alternativas para a reutilização de equipamentos eletrônicos em desuso, de forma interdisciplinar e inovadora contribuindo para o meio ambiente. A partir desta premissa, e o grande número de alunos dispostos a fazer a diferença, o projeto foi capaz de ser inserido como prática recorrente em disciplinas da grade curricular normal. O que inicialmente seria descartado para o lixo, através desta iniciativa, torna-se útil novamente, possibilitando aos alunos envolvido o contato com a interdisciplinaridade, responsabilidade social e o cuidado com o meio ambiente, relacionando o impacto do seu trabalho em beneficio a sociedade e a consciência de sua importância no panorama internacional. 
Esta iniciativa está ligada ao Núcleo de Inclusão Digital (NID), cujo o propósito é, dentre outros, reaproveitar, reutilizar e doar equipamentos eletrônicos em desuso, através de atividades práticas e autodidatas que potencializam e fortalecem o processo de ensino-aprendizagem, desenvolvendo as habilidades cognitivas e interpessoais necessárias para um trabalho colaborativo e bem-sucedido (Vicent et al. 2015).

Através deste Núcleo, incentiva-se práticas multidisciplinares com a colaboração dos cursos de Jogos Digitais, Computação, Engenharias e Design. Os alunos destes cursos trabalham de forma integrada na reestruturação elétrica, nas alterações mecânicas e visuais, na recuperação e adaptação do hardware e software, de modo com que cada aluno possa contribuir com sua respectiva expertise, para que o produto final seja resultado de um trabalho integrado, multi e transdisciplinar.

Ao final, um antigo terminal de autoatendimento em desuso torna-se máquinas de jogos eletrônicos e terminais interativos, com aplicações desenvolvidas pela comunidade acadêmica fomentando atividades interdisciplinares e o processo de desenvolvimento e integração entre cursos com foco no ensino, aprendizagem, responsabilidade sócio ambiental e a colaboração entre as diversas áreas do conhecimento.

\section{O Ensino Interdisciplinar Aplicado de Forma Prática e Colaborativa}

Dada a tendência de ensino interdisciplinar, este trabalho pode fornecer informações úteis para aqueles que pretendem fazer projetos semelhantes, com uma forma inovadora de criar e colaborar com grupos de alunos em cursos de graduação. Hoje existem programas interdisciplinares que concentram em abordagens de sustentabilidade, energia, engenharia e questões globais (Vicent et al. 2015).

De acordo com (Prensky et al. 2007), o aprendizado baseado em jogos digitais, apesar de ser mais frequentemente associado a processos educativos nas escolas poderá ser expandido a universidades e ambientes corporativos, podendo alcançar e afetar públicos mais amplos por fazer o uso de diferentes áreas para a sua criação. Segundo Prensky, o aprendizado baseado em jogos digitais pode ser aplicado, por razões estratégicas, aos próprios consumidores e fornecedores de uma empresa. Logo o desenvolvimento de jogos digitais pertencente a uma das etapas deste artigo, por si só contempla não somente a educação e a interdisciplinaridade, mas a possibilidade de inserção dos alunos no mercado de trabalho, como futuros empreendedores.

Quais seriam as estruturas curriculares e práticas de ensino que ajudariam nossos estudantes a se prepararem para futuras carreiras ambientais? E quais as práticas poderiam serem fortalecidas e adicionadas? As reflexões acima nos convencem que essas práticas de ensino podem ser interessantes para os professores e administradores das instituições de Ensino. Esse estudo proporciona essa oportunidade para explorar essas questões.

\subsection{Integração de Áreas Educacionais}

O projeto desenvolvido visa buscar novas formas de educação com base na integração de diferentes cursos de graduação e formas conscientes da aplicação do ensino com preocupação e responsabilidade ambiental. $O$ projeto desenvolvido foi realizado em uma instituição de ensino internacional integrando o departamento Núcleo de Inclusão Digital (NID) no Brasil, responsável pela reciclagem e doação de 
equipamentos eletrônicos, o departamento de Art \& Design de uma universidade americana responsável por integrar a oficina de pintura de rua em colaboração com a universidade Brasileira bem como os cursos de Computação, Engenharias, Jogos Digitais, Arquitetura e Design oferecidos no pela rede no Brasil. O projeto realizou o intercâmbio de alunos entre os cursos e disciplinas presenciais com o objetivo de realizar a troca de informações e experiências objetivando não somente $o$ desenvolvimento colaborativo, mas compreender a visão do projeto em suas mais diferentes formas de pensar.

\subsection{O NID e Sua Atuação Institucional}

O Núcleo de Inclusão Digital (NID) iniciou em 2015 uma reestruturação interna, tornando-se parte importante da instituição, aderindo não somente a doação de equipamentos eletrônicos a escolas da comunidade de Porto Alegre e o descarte eletrônico consciente mas tornar-se parte integrante do ensino de acordo com a figura 1. No ano de 2016 foi realizado uma força tarefa entre alunos e professores colaboradores com o objetivo de reestruturação e análise de equipamentos depositados para reciclagem. Esta iniciativa resultou na reciclagem de equipamentos eletrônicos de forma sustentável com o total superior a 2.4 Toneladas de equipamentos eletrônicos. $\mathrm{Na}$ figura 1, é possível verificar o depósito de material a ser reciclado pela instituição, assim como a força tarefa realizada entre professores e alunos voluntários.

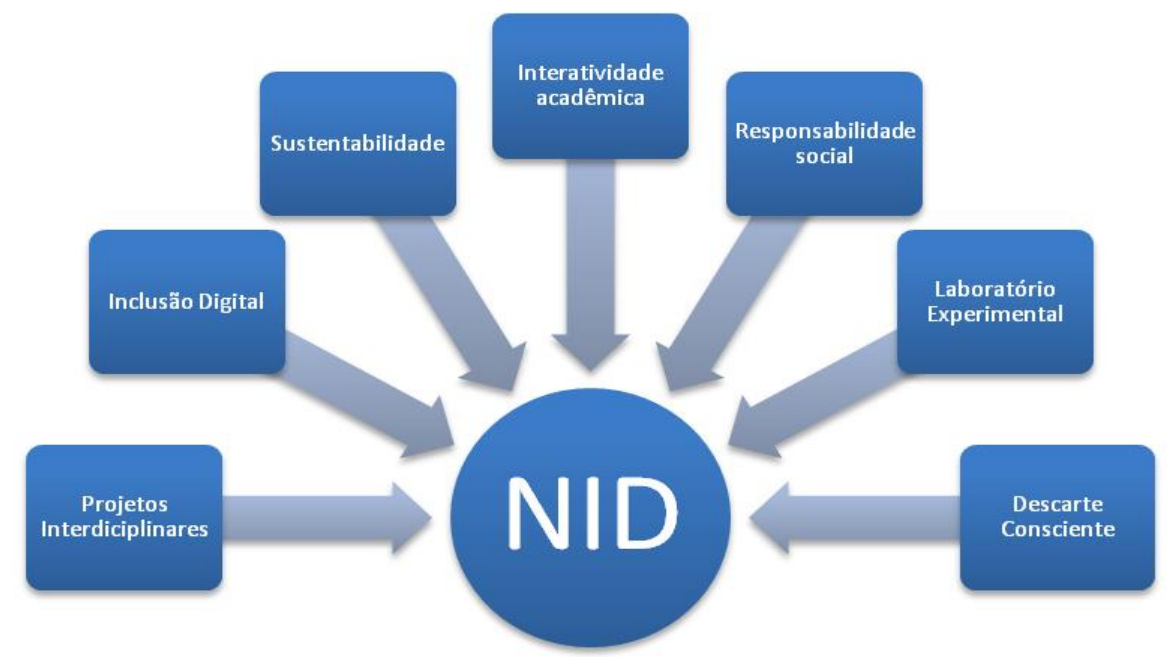

Figura 1. Diagrama de atuação do NID a partir de 2015.

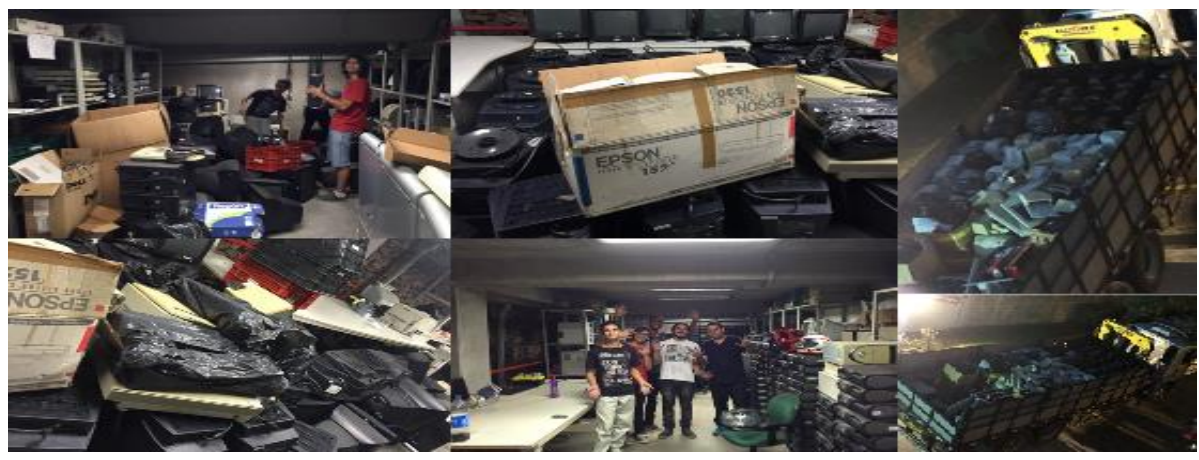

Figura 2. Imagem da Reciclagem de Equipamentos em 2016. 
A participação dos alunos de diferentes cursos na reestruturação do Núcleo de Inclusão Digital (NID), contribuiu de forma efetiva na troca de experiências e possibilidade de utilização do lixo eletrônico em projetos institucionais e sua importância na consciência e formação de um cidadão. Neste momento nasceu o conceito de criação do terminal interativo, nascendo ali um projeto interdisciplinar entre diferentes cursos e culturas em uma única ação, reciclar e desenvolver o ensino de forma responsável e sustentável.

\section{Metodologia}

O trabalho foi desenvolvido em etapas pré-definidas entre alunos e professores de acordo com suas respectivas áreas em encontros presenciais extraclasse que ocorreram semanalmente no turno da tarde. Os professores propiciaram o intercâmbio de seus alunos entre disciplinas de diferentes cursos, integrando o trabalho realizado, sempre que possível, como parte da avaliação de suas respectivas áreas. O projeto foi divido em etapas de desenvolvimento aplicadas de forma paralela e colaborativa de acordo com o diagrama 1 descrito abaixo:

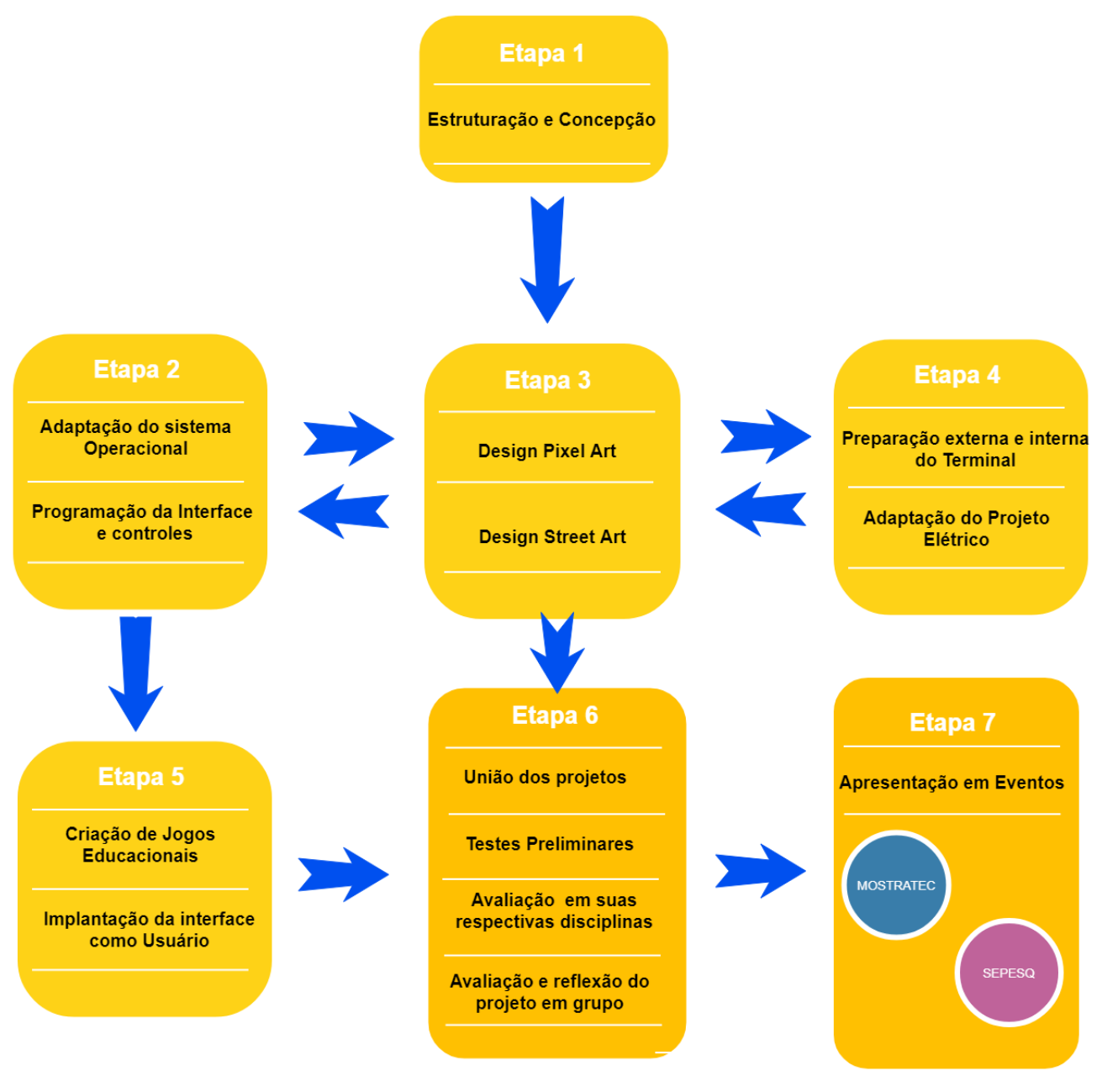

Diagrama 1. Fluxo de Desenvolvimento do projeto Terminal Interativo 


\subsection{Etapas de Desenvolvimento}

As etapas do projeto educacional foram realizadas de forma não linear e colaborativa de acordo com a descrição abaixo:

Etapa 1: O projeto obteve a sua concepção a partir da reciclagem de equipamentos eletrônicos por alunos voluntários de diferentes cursos durante o ano de 2015 e 2016, Figura 3, a partir do estudo e a importância da reciclagem de eletrônicos e o seu impacto ao meio ambiente. A partir desta etapa foi realizado um estudo da importância da educação consciente e o modo que poderia o aluno ser o protagonista da construção do seu conhecimento e não apenas um espectador na formação de suas carreiras de forma sustentável e inovadora.

Etapa 2: Os cursos de computação e jogos digitais se uniram em busca de soluções de qual sistema operacional poderia ser utilizado para a aplicação de diferentes tecnologias envolvendo jogos educativos e terminais interativos. Nesta etapa os alunos realizaram relatórios das diferentes características dos sistemas operacionais em suas mais diversas versões Windows, Android e Linux em ambientes desktop, mobile e internet das coisas. A partir da premissa que os custos de equipamentos deveriam ser reduzidos visando a reciclagem dos equipamentos existentes a versão desktop foi a escolhida por dispor de diversos computadores à disposição. Após a realização do teste de hardware e a montagem do computador em formato de aula ministrada por um professor, dois grupos foram divididos em versões Windows e Linux visando futura comparação entre os projetos de implantação ao ser realizada ao final do semestre.

Etapa 3: Nesta etapa os cursos de Engenharia de Produção e Design se uniram em dois diferentes projetos de arte coordenados pela professora Kaori Tamekuni e professor Claudio Salvalaio por dispor de 3 terminais a serem reciclados. O primeiro projeto consistiu na realização do design com base em Pixel Art a partir de imagem de jogos antigos desenhados com pixels coloridos autoadesivos sobre o terminal. $\mathrm{O}$ segundo projeto consistiu na realização de um curso gratuito e internacional de pintura sobre grafite ministrado entre a universidade brasileira e a americana pertencente ao mesmo grupo educacional, logo propiciando a realização do curso em formato bilingue com o uso de ferramentas educacionais como o Moodle para o compartilhamento de materiais, o Skype para o comunicação de forma síncrona durante a aplicação da técnica de pintura e as redes sociais para a divulgação do trabalho realizado de acordo com a Figura 3. 


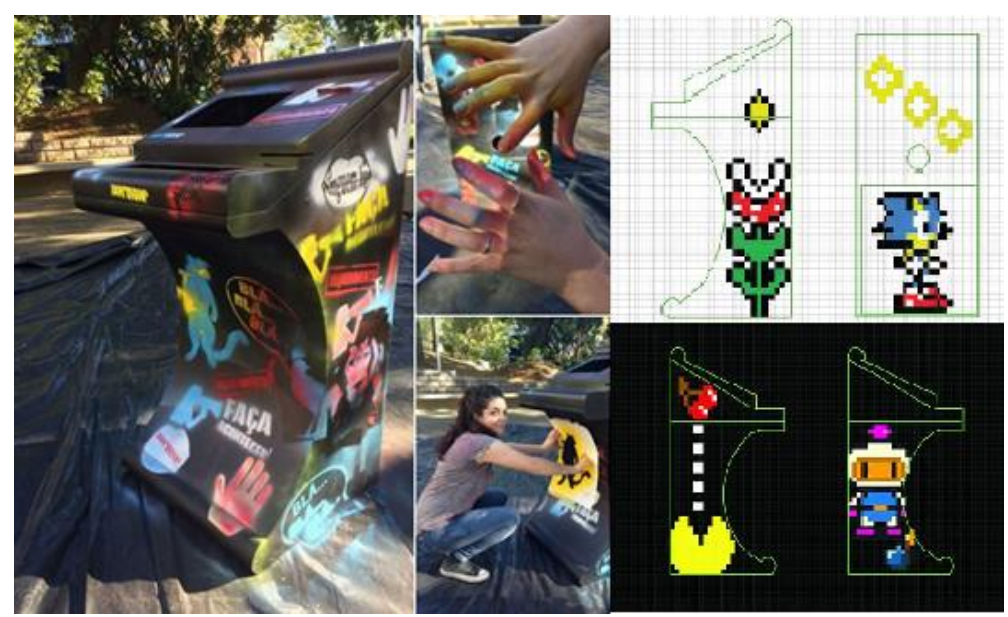

Figura 3. Projeto de Design Pixel Art e Design Street Art

Etapa 4: Nesta etapa foi realizado a limpeza dos terminais e a adaptação do sistema elétrico dos equipamentos internos pelos alunos dos cursos de Engenharia de Produção, Engenharia Elétrica e Mecânica. O terminal consiste em material metálico havendo a necessidade de remoção da pintura anterior a partir de jato de areia, com posterior aplicação de fundo branco e preto com o uso de tintas automotivas à base de óleo como visto na Figura 4. O sistema elétrico consistia na ligação e aterramento de um computador, controle com conexão USB desmontados e adaptados a botões e manche de grande porte como vistos em antigas máquinas de fliperama sobre uma base em madeira. A escolha por estes botões consistia no baixo custo e acessibilidade a pessoas com deficiência tendo em vista o tamanho dos comandos.

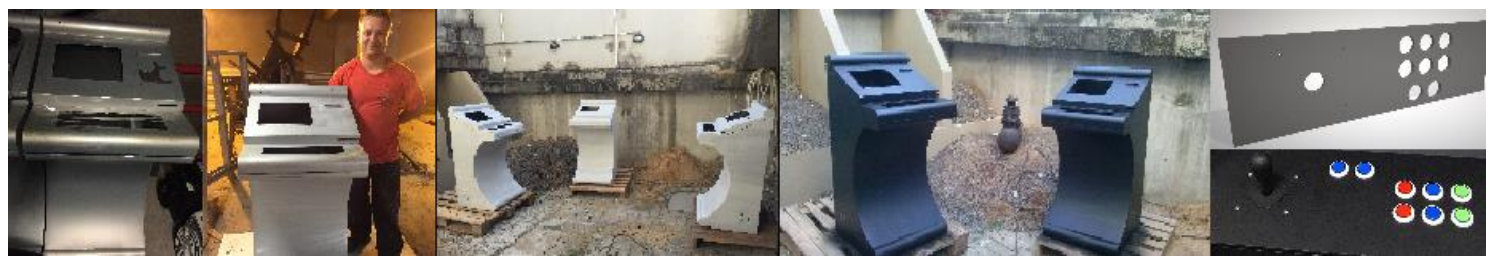

Figura 4. Limpeza, pintura de fundo e base dos controles.

Etapa 5:Nesta etapa, os cursos de computação integrados com o curso de jogos realizaram o software de integração com o hardware e interface visual para a utilização de aplicativos interativos e jogos digitais. A integração do hardware contempla a criação do software de calibração dos controles projetados pela equipe de engenharia possibilitando futuras atualizações por tratar-se de software livre. Nesta etapa, os professores contribuíram com as melhores práticas de interface com o usuário e as tecnologias de compatibilidade multiplataforma de software aberto, possibilitando a criação de novas ferramentas em disciplinas no decorrer do curso.

Esta etapa foi de fundamental importância para os alunos de jogos digitais, que estavam realizando as disciplinas de projetos fossem capazes de testar a efetividade, qualidade e aceitação dos seus projetos/produtos em toda a comunidade acadêmica. Foi este momento que possibilitou que os alunos compreendessem as dificuldades de transformar um projeto de sala de aula em um produto real, assim contribuir para o desenvolvimento de startups entre alunos da instituição. 
Etapa 6: O projeto de Jogos é uma disciplina associada à concepção, elaboração de regras e estruturas que resultam em uma experiência para os jogadores. O trabalho do projetista de Jogos digitais (ou game designer) é, em alguns aspectos, semelhante ao do arquiteto ou ao do diretor de cinema, ou seja, ele se encontra em uma posição de liderança, que tenta resolver a relação dinâmica entre sua visão e aqueles que irão implementá-la. Em linhas gerais, assim como em um software utilitário, um jogo é desenvolvido a partir de seu conceito até a sua conclusão. As etapas específicas podem variar, porém os elementos de alto nível são bastante universais e é aí que o foco permanecerá. Antes de começar o projeto em um jogo, é preciso que se tenha uma ideia geral acerca do jogo, se ele se encaixa no gênero e quais são as metas da sua publicadora. A partir dessas informações, pode-se criar um documento com o objetivo de obter a aprovação para desenvolver o projeto. Todos os artefatos são criados dentro de alguma metodologia de projeto. Seja a construção de um protótipo físico, a elaboração de uma interface de software ou a implementação de uma série de experimentos controlado. As metodologias de projeto orientam o processo de pensamento criativo e ajudam a garantir um trabalho de qualidade.

Nesta etapa foi realizada a união das etapas de forma presencial entre os alunos e professores com o objetivo de realizar uma reflexão dos desafios superados durante o desenvolvimento e a integração de diferentes áreas com foco em um objetivo comum. Em um segundo momento de forma individual, os professores realizaram a avaliação dos relatórios em suas respectivas disciplinas de acordo com o cronograma institucional e ementas pré determinadas pela universidade em conformidade com o MEC. Um dos grandes desafios apresentado pelos alunos bem como a sua maior realização foi como diferentes cursos, olhares e experiências fomentaram o desenvolvimento de um projeto, que mesmo estudantes de diferentes países como Brasil e EUA possuem interesses em comum. A importância no desenvolvimento de projetos em equipe, torna a experiência e o processo do saber algo divertido e único com o uso de novas tecnologias e redes sociais, tornando o aluno o percursos e propagador do seu conhecimento, cabendo ao professor um papel de orientação e coordenação das etapas desenvolvidas ministrando pequenas aulas com base nos desafios propostos, se colocando muitas vezes no papel de aluno em outro curso devido a interdisciplinaridade do projeto.

Etapa 7: O projeto após sua finalização e avaliação em suas respectivas disciplinas, os alunos que fizeram parte do projeto, de forma autônoma, realizaram a amostra de seus trabalhos em eventos na grande Porto Alegre, demonstrando o trabalho realizado para toda a comunidade acadêmica, evidenciando assim que é possível desenvolver projetos inovadores com responsabilidade sócio ambiental de forma integrada, fazendo com que fosse incluído no processo de ensino institucional respeitando as matrizes curriculares, assim sendo protagonista na construção de sua educação não somente como alunos mas como cidadãos.

O produto resultante do esforço em conjunto, dos alunos e professores por si só já materializa os diálogos e negociações que ocorrem em um projeto. Ao simular um processo de concepção e produção dentro do ambiente universitário, costuma-se pensar que a que o projeto está completo quando o produto foi concluído. Porém, existe um caminho que deve ser percorrido e que vai proporcionar outras vivências fundamentais 
na atualidade. A demonstração do arcade em eventos empresariais e acadêmicos bem como a sua devolução como um benefício para a comunidade tem um valor considerável numa perspectiva didática. $\mathrm{O}$ processo de projeto que prevê espaços de exposição valoriza e dá sentido ao esforço dos estudantes. É o contraste entre o trabalho especializado, em um espaço e tempo delimitados com a demonstração em espaço aberto e coletivo. A troca de informações com o público retroalimenta o processo e traz mais elementos para a formação dos estudantes.

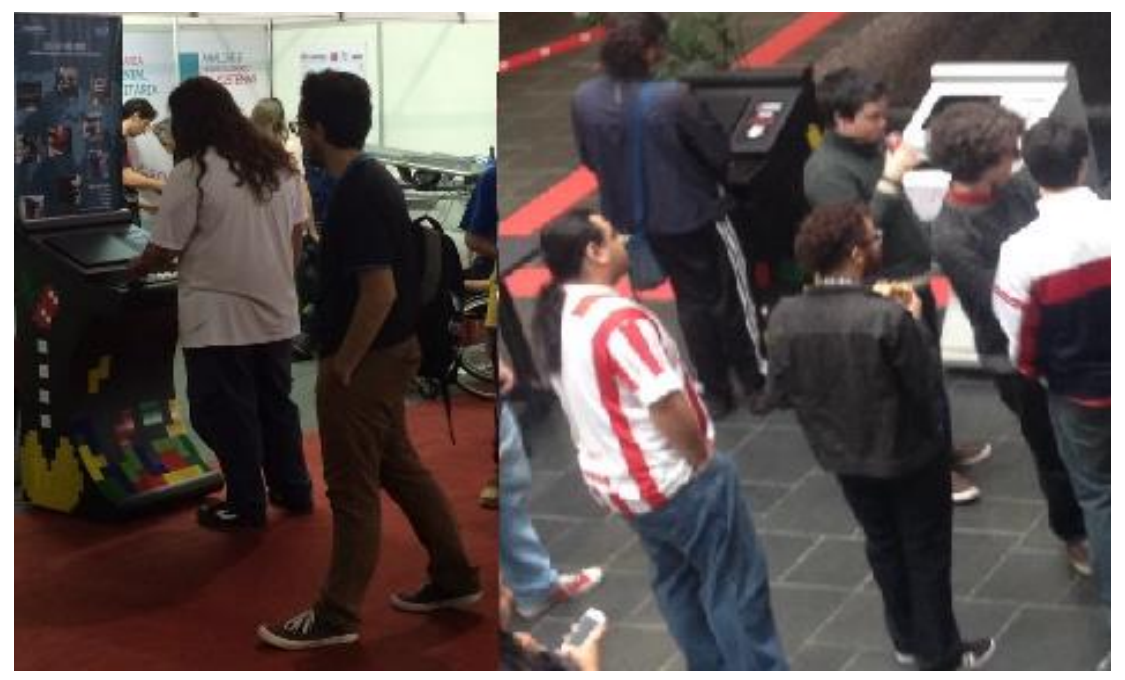

Figura 6. Demonstração do trabalho em eventos.

\section{Considerações Finais}

O projeto atingiu plenamente os seus objetivos, destacando-se a inovação obtida através de uma nova forma de reciclagem que propiciou a interdisciplinaridade entre cursos, trabalho em equipes multidisciplinares bem como o desenvolvimento acadêmico e profissional dos alunos envolvidos no processo, ainda propiciou o empreendedorismo evidenciado através dos testes de mercado dos produtos desenvolvidos em disciplinas regulares e projetos individuais do curso de jogos digitais, integrado com oficinas de âmbito internacional.

No âmbito geral, qualquer item que deixe de ocupar o mananciais, ou acumularse em lixões, para retornar ao mercado, ou ganhar uma nova forma de uso, há de considerar como benefício, tendo em vista a quantidade de lixo que acumula no dia a dia, seja para um destino correto, ou para torna-se parte de pilhas de lixo não tratado que acaba por virar poluição.

A prática extraclasse empregada neste projeto possibilitou aos alunos, de cursos distintos, uma integração onde foi possível que estes experimentassem, mesmo que por um curto período de tempo, um vislumbre de como seria o futuro trabalho em uma empresa, visto que diferentes funcionários com diferentes qualificações, estavam a desempenhar a construção de um objetivo em comum.

Os estudantes que participam dos projetos do laboratório vivenciam processos de desenvolvimento que propiciaram a construção de vários níveis de compreensão pois se envolveram na geração de produtos orientados à inovação.

Do ponto de visto didático pedagógico o projeto proporcionou aos alunos uma forma de aprendizado diferente do vivenciada em sala de aula, onde nesta forma de 
ensino eles eram seus próprios mestres e deveriam buscar por si mesmos preencher as lacunas de conhecimento necessárias à conclusão do projeto. Ainda que sob supervisão de professores, estes alunos estavam livres para explorar os conhecimentos adquiridos e potencializá-los com experiências práticas e enriquecedoras.

O dia a dia em sala de aula apresenta desafios em termos de ensino e aprendizado tanto para alunos quanto para professores. No entanto, aliando-se métodos pedagógicos, as facilidades da computação e os processos de projeto, o ensino de tais conceitos pode se tornar uma atividade agradável e desafiadora, despertando, no educando, a atenção para a importância de processos de co-criação, seja entre os seus pares seja com a comunidade terá no seu dia a dia.

Agradecimentos: A Universidade Federal do Rio Grande do Sul (UFRGS), (IFRS) Instituto Federal do Rio Grande do Sul, (UniRitter)Centro Universitário Ritter dos Reis.

\section{REFERÊNCIAS BIBLIOGRÁFICAS}

GREENPEACE (2015). “The E-Waste Problem", http://www.greenpeace.org/international/campaigns/toxics/electronics/the-e-wasteprproblem/, Setembro 2017.

GREENPEACE (2010). "Greener Electronic", http://www.greenpeace.org/international/en/campaigns/toxics/electronics/, acesso em setembro, 2017.

ORTÁCIO, S. A Sustentabilidade como Meta das Tecnologias de Informação. Revista Conexão, Porto Alegre, 36, pgs 20 e 21, acesso em jul/ago, 2010.

PALOP, JUAN (2010). “Geração de lixo eletrônico cresce a 40 mil de toneladas por ano", http://www.pnuma.org.br/ noticias_detalhar.php? id_noticias=224, acesso em setembro 2017.

PERKINS, D. N.; DRISSE, M. N. B.; NXELE, T.; SLY, P. D. E-Waste: A Global Hazard. Icahn School of Medicine at Mount Sinai. Annals of Global Health. v. 80, p. 286-295, 2014.

PRENSKY, M. Digital Game-Based Learning: practical ideas for the application of digital game-based learning. St. Paul: Paragon House, 2007.

STEP. Solving the E-waste Problem. E-waste Prevention, Take-back System Design and Policy Approaches, 2015.

SILVA, et. al. O Descarte de Componentes Eletrônicos como Oportunidade Empresarial. In: REVISTA RETC - Edição 11ª , revista nº 3, outubro de 2012.

VINCENT S, DUTTON K, SANTOS R, SLOANE L (2015) Interdisciplinary environmental and sustainability education and research: leadership and administrative structures. National Council for Science and the Environment, Washington DC 